\title{
Why neither Russian nor Arabic will Become World Languages
}

\author{
Dennis Michael Bryant (Corresponding author) \\ Faculty of Arts, University of Canberra \\ Kirinari Street, Bruce, Canberra, Australian Capital Territory, Australia \\ Tel: 61-04-0049-9265Ｅ-mail: DrDennisBryant@gmail.com
}

Received: May 16, 2021 Accepted: June 16, 2021 Published: June 17, 2021

doi:10.5296/ijch.v8i1.18650 URL: https://doi.org/10.5296/ijch.v8i1.18650

\begin{abstract}
This paper argues that classical languages, such as Arabic and Russian, are most unlikely to become spoken widely around the world, as has English. This is not to deny that Russia launched a sputnik into space in earlier times and currently is considered to be a super-power. Nor is there any intention to deny that the Russian language once functioned as a diplomatic language. Nor does the premise constitute a denial that Arabic is widely spoken in the Middle East and in some parts of Africa, and is recognised as a carrier of culture. But qualifying for a label of classical does carry a burden.

These comments are not meant to denigrate either Russian or Arabic; they are classical languages in a sense that simplistic English will never achieve. Unlike English, Russian and Arabic both require a complexity of construction which entails strict adherence to building grammatical inflections on nouns, which is called case marking. While such case markings might be seen as concise, and perhaps even elegant word construction, this paper will argue that an over-fondness for expanding the basic words by building upon them case structures that are essentially semaphores to signal grammatical metadata, is antithetical to discourse in so much as it is a departure from simplicity.

In order to demonstrate the likelihood of this paper's premise being true concerning metadata overload at the word level, as is evident in case marking, the methodology is mixed in the sense that it seeks to establish a general probability of feasibility for the premise. This can be achieved through a brief demonstration of two languages which retain case, these being Arabic and Russian, against today's English which jettisoned case in days of yore. Perhaps it is reasonable to suggest that this long-past jettisoning, of case and its overheads in favour of simplification of construction, has contributed to English success in becoming the accepted
\end{abstract}


and widely-spoken world norm.

Keywords: case marking removal, simplification, positional inference

\section{General Introduction to Case}

It might come as a surprise to speakers of English — but English is not a classical language in any sense of the word. It only emerged when European Angles and Saxons invaded England pre the tenth century, and according to Mitchell, the language became known as Anglo-Saxon English but is also called Old English. Providing further background, Potter mentions that Old English had four main dialects, these being Northumbrian, Mercian, West Saxon, and Kentish.

However, Old English is rather different from today's Modern English. Gunn \& Eagleson describe Old English as having 'grammatical devices built into words' [p. 101], or being 'synthetic' in nature. The major change is that English has embraced a sustained move away from the complexity of synthetic construction. Gunn \& Eagleson also point out that today's English is much more 'analytical' in its nature. In this regard, Bolinger remarks that instead of inflating words with inflected endings to show grammatical function, those inflectional endings were 'taken over by prepositions and word order' [p. 118]. An example of this trend to simplicity is the removal of case markings from nouns. Additionally, both Wrenn and Potter note that from the time of King Alfred the Great in the late ninth century, there was an accompanying move towards an agreed word order, beginning the trend towards the order evident in today's English.

Having described a simplification to nouns, it must be said that some case markings can be seen in today's English, but only on pronouns. For example, 'they, them, their' indicate respectively a Nominative (also called a Subject) pronoun; an Accusative (Object) pronoun; and, what has been called for convenience, a Possessive pronoun but is in reality an adjective that describes 'ownership'.

However, it cannot be argued that today's speakers are users of case. The latter statement may seem to be at odds with previous comments and therefore illogical, but it is nevertheless true because, given the demise of case in English, speakers associate a noun's function according to where the noun occurs in a sentence; that is, in today's Subject Verb Object world, as first described by Greenberg, a noun which is positioned in a declarative sentence's Subject slot is seen as undertaking an action, yet when positioned in a declarative sentence's Object slot is seen as enduring an action. In other words, English has acquired a set word order whereas Old English had a freer word order because each noun was inflected with a case ending which indicated its (nominative, or accusative, genitive) role.

In summary, the elimination of case endings on nouns (including case elimination on Nominative and Accusative adjectives), has reduced grammatical expense to speakers in today's English. It is true of course that a trace of past inflections does remain. The lingering inflection that was not eliminated is evident on Possessives where an apostrophe ' $\mathrm{s}$ ' inflection remains today. It should be noted that this paper has intentionally referred to an apostrophe ' $\mathrm{s}$ ' ending as an inflection, and not a case ending. It is necessary to draw this distinction because it is a frequent over-sight that an apostrophe ' $\mathrm{s}$ ' ending serves to convert a noun into a different word type; that is, into an adjective (as in John's). 
It would not be correct to conclude that case elimination was a small gain. Such a gain was major because there were several classes of nouns, each of which had its own set of case inflections. As a small comparison, a much smaller cost of recognising word class and then applying grammatical association is experienced by learners of French where a new speaker has to 'know' the gender of a noun in order to associate a definite article (le, or la). In short, unlike Old English, it is reasonable to claim that today's English has zero case markings, and this paper holds that this zero case marking feature of English is likely to ensure a lower uptake cost for learners, as well as a lower operating cost for all speakers than would be probable in case languages such as Arabic and Russian, or even French.

\section{General Introduction to Arabic Case}

Probably the least-widely known feature of Arabic is that it is a Verb-Subject-Object, or VSO, language. While there is no shame in VSO, very few languages have chosen VSO as their method of organisation. In fact, only a small minority or just five percent of languages have adopted this organisation. Nor does VSO qualify as the second most chosen organisation that is SVO organisation, which accounts for forty five percent of languages. English qualifies as SVO. However, the most widely chosen organisation is the antithesis of VSO, which means that its organisation is SOV, and is typified by Japanese. So, Arabic organisation is relatively unique, where unique might be defined as unexpected and infrequently encountered.

\section{Cases, Consonants \& Radicals}

Unlike English which has a zero tolerance of case on nouns, it is not out of place to expect case in a language that is classified in the Semitic grouping along with languages like Hebrew, Akkadian, Aramaic, Phoenician and Egyptian, which survives today as a liturgical language and is known as Coptic. Langacker points out that Arabic 'has pharyngealized consonants' which means that Arabic sounds can be produced with constriction of the throat [p. 151]. Sapir groups Arabic (along with Finnish and Latin) as a synthetic language and, according to his definition for synthetic, it is a linguistic scenario in which concepts cluster more thickly and words are more richly chambered when compared to, say, English which is in his analytical grouping due to its comparatively minor concern with word construction.

In more specific terms, Tritton notes that Arabic marks one of three case suffixes on a noun [p. 11]. These suffixes are ' $u, a, i$ '. To exemplify, and using 'bayt' as the semantic underpinning for 'house'; the suffixes are nominative ' $u$ ', as in 'bayt-u'; accusative 'a' as in 'bayt-a'; and genitive ' $i$ ' as in 'bayt-i'. It would be remiss to fail to mention that many Arabic nouns are composed of three letters, which are called radicals and in a sense they are pillars because they underpin the words that can be derived. Radicals are usually consonants, but can include non-consonants. In the examples directly above, the radicals are BYT. While BT are obvious consonants, $\mathrm{Y}$ is regarded as a voiced palatal semi-vowel. To continue exemplifying the above discussion, and again using 'bayt' as the semantic underpinning for 'house', 'baytun, baytan' would indicate nominative and accusative indefiniteness; whereas 'al-baytu, al-bayta' indicates nominative and accusative definiteness. An expansion of Arabic definiteness is undertaken in the next section. 


\section{Articles: Definite Prefix (al-) \& Indefinite Suffix (-n)}

At this point, however, the plot thickens in complexity slightly, because the distinction between a definite and indefinite noun has been described by Tritton as fundamental in understanding and utilising Arabic. This description may be inferring that both kinds of Arabic definiteness are unlike English in which a common space within a communication is assigned either for a definite or indefinite article as a free morpheme. Not so for Arabic. One is a prefix; the other, a suffix. Specifically, 'al-' is prefixed to a noun to designate a definite article. Markedly contrasted by its different placement, an indefinite article is indicated by a suffixed '- $\mathrm{n}$ ' and this indefinite article is referred to in Arabic grammar as nunation. Here, a minor point of agreement between Arabic and English exists in that a definite article exceeds in character length the size of an indefinite article. Seemingly, between Arabic and English, there is an unstated but shared psychological reality that a single instance requires a minimal investment in character expenditure.

The following Arabic sentences serve to exemplify the above discussion. However, two features of Arabic are missing in the following examples - these being the Arabic script, and because the script is not being used, the convention of writing from right-to-left is also absent. It uses 'rajul' and 'kelb' as the semantic underpinning for 'man' and 'dog'.

Consider a definite example in which 'the man kicked the dog'.

$\begin{array}{llll}\text { Verb } & \text { Subject } & \text { Object } \\ \text { Rakala } & \text { al-rajul-u } & \text { al-kelb-a } & \text { (hyphens are used only for clarity). } \\ \text { 'Kicked } & \text { the man } & \text { the dog' } & -- \text { is the order of expression, or VSO. }\end{array}$

As regards the verb in the exemplar sentence above, it shows 'rakala' as the past tense form for 'hit'; is interpreted as masculine third person and is a default interpretation in the absence of other inflections; and is required to agree with the following nominative noun in Number, Person and Gender. Speaking of Gender, were the noun to be feminine, then the verb would need to indicate a non-default feminine suffix which in this case is ' $t$ ', giving 'rakala-t'.

Moving to the second element, the Subject shows two inflections; the first of these being the definite article 'the' prefixed to 'man'. The final Subject inflection is a suffix to indicate that 'man' is to be interpreted to function nominatively. Similarly, the Object, as the third element, has two inflections which are: a prefix to indicate definiteness; and a suffix to indicate that 'dog' functions in an accusative role.

Moving now to an indefinite example in which 'a man kicked a dog'.

Verb + Subject + Object

Rakala + rajul-u-n $\quad+$ kelb-aa-n (hyphens are again used for clarity).

As regards the verb in the exemplar sentence above, the example again shows 'rakala' as the verb. Moving to the second element, it is noticeable that the Subject now lacks a definiteness prefix. However, it does have a word-final indefiniteness marker '-n' which occurs as the outer-most suffix. Perhaps the best explanation for ' $\mathrm{n}$ ' as the outer-most suffix is that the 
inner-most suffix ' $u$ ' is a higher level case indicator, and if this interpretation is taken, then it would follow that an indicator of lower importance can be relegated to an outer position thereby being isolated from the nominal root. This seems to be a nice piece of Arabic symmetry of thought.

Further exploring Arabic paradigms, the next exemplar is restricted to a sentence fragment, namely, a Subject which uses 'baab' as the semantic underpinning for 'door' in a construct meaning 'a door of a house', as taken from Tritton.

\section{Subject}

\section{$\underline{\text { Baab-u }+ \text { bayt-i-n }}$}

The first element of the exemplar above, 'door', lacks a definite article prefix, and this gives rise to the inference that this construct is likely to be indefinite. As regards grammatical function, the first element is suffixed with a ' $u$ ' which is indicative of nominative.

Moving now to the final element, 'house' lacks a prefixed definite article and this gives rise to a similar inference that this construct is likely to be indefinite also. As regards this element's two grammatical functions, it is suffixed firstly with a '-i' indicating genitive. However, a further inflection is manifest on this final element. An indefinite article is indicated by the '-n' suffix, which sits just beyond the previously mentioned genitive suffix. Taking both suffixes into account, the construction reads literally as 'door' with Nominative suffix + 'house' with genitive suffix, followed by indefinite suffix. According to Tritton, this construct would be translated as '[a] door of a house', but could be rendered more simply and economically in English as 'a house door'. Although not shown above, a modifying adjective cannot come between the two construct nominals; instead, an adjective agreeing with the first noun must come after the second noun; that is, adjectives are placed post the construct.

In summary, Tritton remarks that this genitive arrangement is called a construct state which means that the governing noun comes first but loses nunation. Additionally, while the governing noun makes no comment on definiteness, an assumptive alliance between the noun construct must be presumed based on the definiteness of the genitive noun [ibid, p. 34]. As a summation, and revealing a degree of article balance, 'al-' is a definite prefix, while '- $n$ ' is an indefinite suffix that follows a case ending. Having noted the aesthetic, such construction does come at a cost. In fact, for some types of noun, Tritton notes that the learning of inflection 'is all memory work... because no rules can be given'.

There are, of course, markings for dual and plural number. With respect to dual, perhaps less ironic than it may seem, there are two markings. These suffixes are 'aani' for nominative, with 'ayni' functioning for both accusative and genitive. To exemplify, consider using the semantic underpinning for 'eye', '?ayn'. Its three radicals are firstly a seeming question mark but representing a glottal stop, which somewhat recalls to mind the Cockney speech found in London. By custom in Arabic, the glottal stop is attached to a vowel -here ' $a$ '. The remaining radicals are $\mathrm{Y}$ and $\mathrm{N}$. With a dual suffix, 'two eyes' would be expressed as nominative '?ayn-aani', and as accusative-cum-genitive '?ayn-ayni'. 
At first sight to speakers who are not familiar with Arabic, '?ayn-ayni' may be a bit of a tongue-twister, but a native speaker would be unlikely to find them to be similar because they differ markedly, in that '?ayn' is a visual reality that occurs only with eyes, whereas the 'ayni' inflection usage can occur across any nominal for which duality is possible. Perhaps the following example is dissimilar in nature, but English itself may often represent difficulty of interpretation to Arabic speakers -for example, when nominals function in English as verbals without carrying any change in form. For example, as a verb in 'He would run often', yet as a noun in 'I got a good run with my shares'.

Apart from these case markings, and possibly serving as a testimony to human ingenuity,

Arabic distinguishes its nouns according to grammatical gender, although natural genders can be found. For example, masculine as in 'malik' (king) and feminine 'malikah' (queen). In addition, a noun can carry an inflection for number, being either singular (usually assumed to be the default), or inflected as dual (as mentioned), or inflected as plural. And not forgetting definiteness, nouns can be marked as either Definite or Indefinite. There is a small pool of so-called 'deficient nouns' which escape case marking but nevertheless do require definiteness marking. Additionally, there is a requirement for marking agreements in the nominal sphere; that is, adjectives are marked in agreement with their accompanying noun markings.

The previous section, as brief as it was, points to one implication: this being that the presence of case infers a slower uptake, and a higher operating cost is probable for learners of Arabic than would be the case for learners of English. If this is true, as this paper proposes, then construction cost in Arabic can be considered to be an inhibiting feature; as it is in other languages which require the complication of case constructions. However, this claim is not intended to deny Sapir's tenet that Arabic is a significant carrier of culture; nor does it dispute that words have been borrowed from Arabic into English, such as 'algebra' which has caused the ire of many high-school students.

\section{A Mention of Russian Case}

Unlike the English drive towards achieving zero tolerance of case markings, by contrast, it has been observed by Wade et al., as well as Mustgo, that the Russian language is well-endowed with six markings to distinguish a noun's case function. This means that there are declensions on nouns. Declensions are also known as case markings which are used to indicate a Nominative (or, subject) noun; or an Accusative (a direct object, which is the most usual situation); or a Dative (an indirect object), which occurs when a verb requires a second object. In English such a verb would be 'donate'. Russian noun markings are also used to indicate Instrumental case (indicating what instrument was used); and Prepositional case (indicating that the noun is used as part of a prepositional construction). Additionally, Russian includes a Genitive (which is a term that is equivalent to Possessive) inflection.

In further signs of complexity, adjective-noun agreement is required and there are rule-sets as to how agreement inflections are completed; and with regard to verbs, there are multiple conjugations. As an additional point, and serving as a contrast to English, there are several 
acceptable orders, and SVO is described as the neutral order. Mustgo reflects that word order is principally determined by topic (what the sentence is about, or old information) and focus (new information).

When compared to an absence of case markings in English, the existence of case markings on Russian nouns, and adjectives, could be interpreted to indicate that a slower uptake and a higher operating cost for speakers is probable. Perhaps ameliorating some of this cost to speakers is that Russian requires neither indefinite nor definite articles. Two additional hurdles exist as script, where Cyrillic alphabet is in use; and, Russian allows personal pronouns to be dropped because the verb ending makes the person clear. These are also potential impediments to global uptake.

\section{Loss of Case in English}

While today's Russian and Arabic languages deserve to be seen as classical languages, it would hardly be a winning argument to view today's English in the same classical light. This is due to the sustained English drive towards achieving zero tolerance of case markings. However, if one were to harken back in time, Old English could be argued to have many similarities to today's Russian and Arabic. In particular, Old English had an extensive set of case markings (nominative, accusative, dative and genitive) on nouns as well as on adjectives. Noted by Mitchell, Old English also distinguished nouns by gender, examples of which would be 'staan' (stone) being masculine, singular and nominative; with 'word' (word) being neuter, singular and nominative; and with 'yiefu' (gift) being feminine, singular and nominative.

However, with the passage of time, Wrenn observes that English has opted for simplicity by sacrificing all its noun and adjective case markings, with one exception -- it has kept some of its pronoun case forms, as in 'they, them, their'. English managed to largely discard the case concept by opting for a much simpler solution. English speakers decided on what this paper would like to call positional inference. That is, a noun appearing in the Subject position is assumed to be a nominative noun; whereas it would be assumed to be an accusative, or a dative noun if it were to appear in the Object position of a declarative sentence. That is, the form of a noun has lost a good deal of relevance and the noun's function is now determined by position.

This trend to simplicity — which Wrenn calls 'the period of lost inflections' - did not happen over-night. Simplification can be traced back to the Anglo-Saxon era and the times of Boewulf and Old English; continuing into Chaucer's and Shakespeare's Middle English before reaching today's Modern English. To name just one example, 'thou, thee' have been discarded from common usage.

Mitigating against the historical shedding of grammatical structures thereby creating a pathway to greater simplicity and reduced speaker effort, English has not managed to shed all classes. For example, some old verb forms still persist and because of their ability to endure are called 'strong verbs'. One example would be 'taken' with its three forms of 'take, took, taken'. However, while they are the exception to a clean-up process that English has revelled 
in over time, they can be explained as high-usage words, and as such they tend to endure.

Notwithstanding the exceptions, it would follow that a clean-up might well be called a simplification process. If this statement is true as this paper is intentionally inferring, then it would follow that a sacrifice of grammatical-rule overheads is likely to have repercussions for the process of acquiring that language. In other words, fewer grammatical overheads is likely to assist the uptake of that language, as well as assist daily fluency efforts.

This paper argues, as do other papers by Bryant that are listed in the References section, that part of the linguistic reason for the rise in the use of English was simplicity; or put differently, it never was a classical language in that it never made serious efforts of preservation of what might be called inhibiting case structures. In these senses, it might be reasonable to claim that English is anything but classical. However, it is not being argued entirely that being simplified is sufficient to make English global. Historical circumstances, such as the rise to prominence of the British and then a further rise in global prominence by America would be sustainable as an answer to its rise in popularity. This is certainly the view held by Wrenn. The only thing that English appears to have provided was a relative simplicity of operation; but nevertheless that simplicity may have partly contributed to its world-wide up-take.

\section{Conclusion}

This paper started with a premise that the Russian and Arabic languages are unlikely to ever become spoken widely around the world, as has English. In advancing this premise, it was never the intention of this paper to disparage either Russian or Arabic, for any reason. Instead, there is a recognition herein that both of them qualify as classical languages that have, and still do, serve their speaker base. However, there is an obvious irony here, namely, that a non-classical language arose from obscurity into ascendency, becoming the first choice for universal communication - that language is English and it is notably not one of the classical languages. In a sense, and speaking allegorically, English is like the awkward Ugly Duckling that developed into a graceful and elegant swan that was poised, most unexpectedly, to soar.

The rise of English would seem partly attributable to economic development of England and also to the rise of the United States of America; however, this paper did not pursue arguments along political or economic lines. Instead, this paper put forward an assertion that a label of classical does imply a complexity that entails strict adherence to building grammatical inflections, which are known also as case marking of nouns, adjectives and pronouns. A part of this paper's premise is that a rise in commitment to grammatical inflections comes hand-in-hand with a rise in communicative expense. Continuing the premise, a rise in communicative expense infers the possibility of a lower threshold of acclaim for selecting a language to function as a universal lingua franca.

In order to support the probability of this paper's premise being true, the methodology was theoretical in the sense that it sought to underscore the probable reasons for English becoming a universal lingua franca; namely, that English pursued a strategy of achieving simplicity by discarding costly structures such as case. This flight to soar to world heights did not happen over-night. This trend to simplicity and ease of use can be traced from Old 
English into Middle English before reaching today's Modern English, which now serves as the accepted and widely spoken norm. The irony is that classical languages, for instance Russian and Arabic, have neither reached, nor are they likely to attain, that same milestone within the foreseeable future.

\section{References}

Bolinger, D. (1968). Aspects of Language. New York: Harcourt, Brace \& World, Inc.

Bryant, D. M. (2019a). Focussing on Promotion in English Sentences to Inform ESL Educational Practice. Language, Literature and Culture, 2(3), 102-107. Retrieved from http://www.aascit.org/journal/archive2?journalId=932\&paperId=7371

Bryant, D. M. (2019b). Focussing on Building up ESL Perception of Verbal Slot Complexity to Inform Educational Practice. Language, Literature and Culture, 2(3), 127-132. Retrieved from http://www.aascit.org/journal/archive2?journalId=932\&paperId=7622

Bryant, D. M. (2019c). Focussing on Decoding Contractions in English Sentences to Inform Educational Practice. International Journal of Culture and History, 6(2), 90-101. https://doi.org/10.5296/ijch.v6i2.15892

Bryant, D. M. (2020a). The Form and the Function that Defines and Associates Definite and Indefinite Articles in English Grammar. International Journal of Culture and History, 7(1), 30-40. https://doi.org/10.5296/ijch.v7i1.17213

Bryant, D. M. (2020b). Pursuing the Energetic yet Enigmatic Particle that Powers English Communication. International Journal of Culture and History, 7(2), 38-46. https://doi.org/10.5296/ijch.v7i2.17488

Bryant, D. M. (2020c). Focussing on Revealing English Grammar's Conceptual Unity amidst its Operational Diversity. Language, Literature and Culture, 3(2), 8-14. Retrieved from http://www.aascit.org/journal/archive2?journalId=932\&paperId=7825

Bryant, D. M. (2021). The Chequered History of the Prodigal 'you' Pronoun. International Journal of Culture and History, 8(1), 52-60. https://doi.org/10.5296/ijch.v8i1.18271

Greenberg, J. H. (1973). Some Universals of Grammar with Particular Reference to the Order of Meaningful Elements. In J. H. Greenberg (Ed.), Universals of Language (pp. 73-113). London: MIT Press.

Gunn, J. S., \& Eagleson, R. D. (1966). Survey of language. Angus \& Robertson, Sydney.

Langacker, R. W. (1973). Language and its Structure: some fundamental linguistic concepts (2nd ed.). New York: Harcourt Brace Jovanovic, Inc.

Mitchell, B. (1995). An Invitation to Old English and Anglo-Saxon England. Oxford: Blackwell Publishers Ltd.

$\begin{array}{lllll}\text { Mustgo. } & \text { Retrieved } & \text { May } & \text { 14, } & \text { 2021, }\end{array}$ https://www.mustgo.com/worldlanguages/russian/russianlessons.net 
Potter, S. (1950). Our Language (2nd. ed.). Harmondsworth, Middlesex: Penguin Books.

Sapir, E. (1921). Language: An Introduction to the Study of Speech. New York: Harcourt, Brace \& World, Inc.

Tritton, A. S. (1973). Arabic-Teach Yourself Books. The English Universities Press Ltd., Aylesbury, Buckinghamshire.

Wade, T., Gillespie, D., Gural, S., \& Korneeva, M. (2020). A Comprehensive Russian Grammar. John Wiley \& Sons (UK).

Wrenn, C. L. (1949). The English Language. London: Methuen \& Co. Ltd.

\section{Copyrights}

Copyright for this article is retained by the author(s), with first publication rights granted to the journal.

This is an open-access article distributed under the terms and conditions of the Creative Commons Attribution license (http://creativecommons.org/licenses/by/4.0/) 